\title{
NADAR LA MÚSICA DEL PENSAMIENTO UNA POÉTICA
}

\section{Osvaldo PICARDO'}

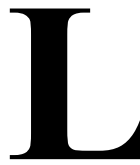

\section{a dificultad del póquer}

Cuando me hablan de una poética personal, al igual que cuando me dicen «poeta», sospecho que he sido invitado a una mesa de póquer. Y no soy un buen jugador de cartas y es seguro que pierdo. Si conservás cierta inicial ingenuidad literaria, el título de «poeta» —con o sin mayúscula - encierra una imagen rodeada de genialidad, vecina al mundo de cantautores y bohemios, el mundo contracultural y under. Es una imagen a la que apostaron con éxito la publicidad y el mercado. El problema con eso ya no es la ingenuidad, sino la edad y el oficio que supera toda clase de pretensiones de genialidad y de ansias rejuvenecedoras. Uno descubre que son muchas más las veces en que el fracaso acompaña la escritura y que no existe garantía ni promesa de éxito que resuelva el horaciano «exegi monumentum aere perennius». La verdadera poética consiste en hacer lo mejor posible el trabajo diario de escribir con conciencia y de leer sin prejuicios. Y eso necesita mucho tiempo, mucha atención y también amor y humildad.

Por eso una poética personal, creo que requiere de algo más que de una buena mano en una partida de póquer: es cuestión de una vida dedicada y comprometida con la poesía.

\section{Soy otro y el mismo poema}

Como alguien dijo — alguien seguramente conocido y ya muerto-, «todo está dicho y llegamos demasiado tarde». De ahí que hablemos por boca de otros y sobreescribamos un poema inconcluso que nadie alcanzará a leer sino de a pedazos. ¿No es esa la primera limitación que debemos asumir? Lo nuestro es escribir entre comillas, citar, aún no sabiendo que citamos: «una cita es una cigarra, no calla nunca, retiene el aire y no lo suelta», decía... Extraña cosa es que encontremos placer en una

\footnotetext{
${ }^{1}$ Osvaldo Picardo (Mar del Plata, Bs.As., Argentina, 1955) docente e investigador universitario, exdirector de la Editorial de la Universidad Nacional de Mar del Plata (EUDEM) y codirector de la revista La Pecera. Algunos libros de poemas publicados: Quis quid ubi: Poemas de Quintiliano (1998), Una complicidad que sobrevive (2001), Mar del Plata (2005 y 2012)”, Pasiones de la línea. Poemas de Nicolás de Cusa (2008); O.P.Vida de poesía (2008), y 21 gramos (2014). Ha traducido junto a F. Scelzo y E. Moore The love poems de James Laughlin y otras versiones suyas de E. Pound, D.H.Lawrence, M. Yourcenar o K. Rexroth han sido publicadas en revistas y en periódicos. Recientemente publico Poesía de Pensamiento. Una antología de poesía argentina (Ed. Endymion, Madrid, 2015).
} 
charla, siempre interrumpida, fragmentaria e incompleta, pero ¿no es eso la poesía: interrupción y reinicio? Entablamos un diálogo que se había roto por siglos, cambiamos de dirección hacia el silencio, desalentados, satisfechos, metafísicos o triviales, y con todo ello, alimentamos esa larga amistad, esa «pura alegría» horneada en el fuego lento del dolor, la injusticia, la muerte.

¿Una ruta? ¿Una carrera literaria? ¿Una profesión de la palabra? No, una ilusión desvanecida de belleza, que te esforzás por imaginar ante constantes fracasos. Ahí me reconozco: «soy otro» y el mismo poema.

\section{Escribir por lo que uno piensa}

En la literatura contemporánea, hay un ejercicio de parodia intraliteraria, en lugar del ejercicio de la escritura. Nos metemos adentro y gozamos de endogamia, como si todo el universo estuviera limitado a nuestros amigos, críticos conocidos y demás colegas. A veces es una exigencia de profesionalismo, inevitable en la industria y el mercado editorial. Y en todo ello, crece un falso pudor autobiográfico de no creérsela, una artimaña social de legitimación y necesidad de reconocimiento. $\mathrm{O}$ bien, se da el autobombo: hablar de uno mismo en tercera persona, o la falsa modestia, o la ironización biográfica, o la diatriba, etc. Son fenómenos de larga y vieja data que cultivaron grandes escritores de todos los tiempos. No están mal ni bien. Pero hoy llega a ser una nueva figuración a tono con los tiempos de sospecha e intolerancia contra los relatos autónomos y seguros de sí. El mercado y la crítica literaria alientan y ofertan catálogos variados de novedades de este tipo. Pero un éxito verdadero no debería consistir en que un libro logre alcanzar fama y notoriedad por estar en esos catálogos.

Es una pobre cosa escribir por el mercado y no por lo que uno piensa.

\section{La mirada de la mujer de Lot}

El presente siempre fue una paradoja compleja y ardua. Nos propone un recorrido por las ruinas que la modernidad y el neoliberalismo han dejado en lo contemporáneo. Pero ¿qué cosa es lo contemporáneo? No es la novedad ni la actualidad con que los suplementos literarios y las revistas especializadas nos venden literatura. Un lector de poesía puede ser contemporáneo de Lope de Vega o de Homero, sin moverse de su presente. Del mismo modo, es contemporáneo el escritor y su obra. Entre los ruidos que producen la urgencia cotidiana, el mercado y el consumo, la experiencia del tiempo propio e íntimo parece una historia disminuida, sin épica ni lírica. Por eso, algunos intentamos crear una línea de fuga que avanza entre las cosas y conecta tiempos y espacios, hombres y animales, basura y arte, naturaleza y ciudad.

Escribir corresponde hoy a la mirada de la mujer de Lot. No es Orfeo quien se da vuelta en nosotros. No dejamos atrás al amor, atrás queda la destrucción. Y ¿adelante? Lo que el ruido no logra ocultar. 


\section{Nadar mar adentro}

Cierta poesía que me gusta, me advierte que existe algo extraño - y también misterioso - como el silencio del cielo estrellado de Pascal o, mejor aún, como cuando, al nadar, te alejás de la orilla, mar adentro. Atrás queda el oleaje y el vocerío de la playa, sólo te acompaña tu propia respiración y germina algo desde abajo y también desde arriba. Cuando nadás solo en mar abierto no se trata de alcanzar el más lejano horizonte ni de recordar dónde quedó la más cercana orilla, flotás entre dos fondos. Y eso, te empuja a un pensamiento, a una música que te mantiene a flote.

A veces, siento que así es la poesía. Y también, nuestra pequeña, breve historia.

\section{Una poesía de pensamiento}

Si debo elegir una línea o tendencia, antes que una poética, encuentro un lugar menos incómodo en lo que algunos hemos dado en llamar, en Argentina, «poesía de pensamiento». No se debería entender como la estética de una época y una generación; en realidad, la lectura de este tipo de poesía responde a estéticas e ideologías de las más variadas y contradictorias. Es, entonces, una constante, una transversal a los siglos: la encontramos ya en Heráclito y luego, en los místicos, los barrocos, pasando por los metafísicos, por los románticos como Wordsworth y Novalis, hasta alcanzar a Unamuno, Borges, Cernuda, Juarroz o Giannuzzi.

En realidad, todos esos poetas son distintos, pero sus poemas tienen una misma actitud, un pensar sintiendo y un sentir pensando.

\section{El temple del espejo}

La actitud de la que hablo parece corresponder al difícil y lábil término alemán de Stimmung, traducido muchas veces por 'temple'. Esta poesía quiere decirnos otra cosa además del tema o el contenido. No es solamente la representación en la superficie del espejo. No se reduce a la comunicación de un mensaje secreto que apenas unos pocos saben. Está forjado por un temple con el que contagia y dispone a un modo de verdad. Es, en acto, un pensar que se hace realidad únicamente en la forma en que se piensa. La fusión íntima de contenido y forma, el cómo de la participación en el lenguaje no puede traducirse. Siempre es para el poeta y el lector una experiencia singular. No significa que no pueda compartirse ni leerse en público; no puede simularse, porque exige tanto para el lector como para el poeta un estado de pensamiento auténtico, un modo de ser y también una disposición frente a sí mismo y al mundo.

De ahí que los poemas parezcan menos líricos y sentimentales, porque proponen un salto fuera de uno mismo, un espejo inquietante que pregunta sin esperar respuestas. 


\section{El corazón de la vida quedó afuera}

La imposibilidad de una respuesta no implica necesariamente lo inefable. En la era de la comunicación todo se publicita como inefable. En realidad, el lenguaje se vuelve semejante a un espectáculo, busca efectismo y visibilidad, pierde su autonomía y libertad. Eso de que nada está afuera del lenguaje, etc. es mentira. Se gastan las palabras hasta el punto que no es fácil decir algo... Entre esas cosas que están afuera, está el corazón de la vida.

¿Cómo funciona la poesía, entonces? Devuelve las cosas al silencio y piensa... Tarea difícil de Adán y siempre a medio hacer.

\section{La distancia que crece}

La tarea del poema conduce muy lentamente — toda una vida - a una relación particular con las cosas, un modo de tratarlas y, sobre todo, de sentirlas y pensarlas: «Esa inteligencia ardiente» que «puede tomar y consumir una zona de la realidad e iluminarla»... Nunca hubiera sido posible ese mundo sin el texto. El poema devuelve una experiencia de la que sabíamos poco, o mejor aún, es la

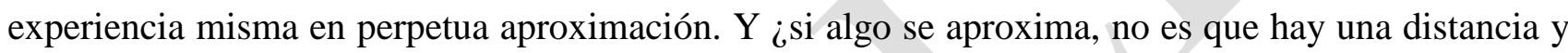
«la distancia no es la belleza del alma»? Es ahí, ahora, que «el creador legítimo tiende a ponerse a un costado de lo creado», y toma distancia. El pronombre vos en lugar de tú, la mirada asombrada y no el aburrimiento ante lo cotidiano, la ironía como única resistencia contra la resignación, la naturaleza tan lejana en el vecino gorrión... La mano del alfarero no deja sus dedos en la obra. ¿Cómo distinguir al bailarín de la música que está bailando?

Todo esto se aproxima al lugar del que el autor se aleja. Y ocurre que, otra vez, Titiro y Melibeo hablan de la ciudad distante.

\section{La experiencia moral de la poesía}

La poesía - se quiera o no- adquiere un compromiso de conciencia con un modo de belleza y de verdad; asume una conducta ante los hechos y las palabras. Por eso «el poema - cito a un poeta argentino- es, además de un objeto, una experiencia moral». Sobrevive a las diversas y adversas épocas de la humanidad; su sola manifestación crea una tensión ética que incomoda o al menos, desacomoda. No hay lugar para la indiferencia o el cinismo. Y tal vez, el rincón al que se desplaza bajo la sombra del mercado editorial, ese grado de invisibilidad al que lo destierran los dispositivos de la industria y de la crítica literaria, no sean sino una de las características que debe a esa conciencia. En cierto modo lo invisible así como lo visible pueden ser un problema moral antes que óptico, literario o comercial. Quiero decir que toda esta constante transhistórica de poesía de pensamiento no deja de ser una elección ética, un estado — en mayor o menor medida - de conciencia enfrentada al mundo y preocupada por valores humanos, sus propósitos y significados.

El poema habla con el idioma de los sobrevivientes: el idioma de quienes aún tienen lo que han perdido. 


\section{La invitación de una inteligencia serena}

«Un terremoto continuo o una fiebre eterna» no permiten ni siquiera el pulso para afeitarse tranquilo. Por eso, no es cierto que el sentimentalismo, ni las pequeñas diferencias narcisistas puedan considerarse garantía de intensidad o de emoción lírica: entre las posibilidades del poema —a veces de un solo verso- está la de sacarnos de nuestra comodidad habitual y revelar «el lado oscuro del corazón». Pero también, existen otras posibilidades menos grandilocuentes y demostrativas, como la de hospedarnos en un simple y humilde pensamiento; es decir, disponernos a una entrega que depende de la invitación que hagamos. El trabajo transpirado con las ideas — por más realista o lírico que fuere- necesita de una inteligencia serena. No siempre estamos seguros de ¿qué cosa es un poema? Talleres, cátedras, premios y festivales de poesía han reemplazado ruidosamente la lectura sosegada y solitaria de ese género literario que, como ningún otro, enfrenta al lector con su «ambigüedad ingénita».

Es peligroso dejar escrito lo que está mal escrito, aunque como decía alguien: hacer malos versos trae a veces, más felicidad que leer los más bellos poemas. No deja de ser una elección y un riesgo.

\section{La fiesta del sentido}

La cuestión a resolver no es solamente experimentar con la lengua en lugar de hacerlo con el sentido, sino buscar responder a las exigencias naturales de los dos componentes, captar sus amistades, sus ritmos y rivalidades. Hay una vida íntima entre los dos y no siempre estamos invitados a sus fiestas. Y cuando eso sucede, hay que esforzarse en comprender la alegría de las palabras y el secreto del silencio. Un poema puede llegar a ser original, innovador o desafiante sin necesidad de forzar el lenguaje o de exagerar rompiendo reglas. Existe en cada ocasión, entre significante y significado, un equilibrio que debemos encontrar. Lo vemos claramente en los poemas de las diferentes épocas o en las etapas de un autor. La proporción secreta entre forma y contenido responde a la necesidad del poema y no siempre logran un punto de reposo. No hay recetas únicas cuando el sabor no depende del gusto de una generación o de una escuela. Encontrar el punto medio corresponde a lo que llamamos precisión: un efecto del lenguaje que si bien no es algo exacto ni científico, es una búsqueda por hacer corresponder proporcionalmente significado y significante.

La fiesta del lenguaje es siempre una fiesta con sentido.

\section{Poesía es lo que se está viendo}

La época y la poesía, el lenguaje y la historia, la naturaleza y el hombre son problemas, no temas. Aparecen desdibujados sobre una constelación de percepciones que empujan a hablar, y no siempre se concilian con las exigencias del poema. «Poesía / es lo que se está viendo». Pero las primeras palabras de lo que se ha visto no siempre quedan al principio del poema. Estuvieron en el final de una contemplación y en el inicio de una meditación, pero se desplazan irremediablemente hacia otros lugares del poema, o apenas son su evocación. Buscan siempre su «forma orgánica» entramada a una 
ambigüedad que llamamos metáfora, imagen, metonimia, fraseo métrico, tono, música de las ideas, etc. Y la ambigüedad es una paradoja: no cesa de aproximarnos a la extensión elástica de lo interpretable. La poesía es por lo tanto, «una complicidad que sobrevive». Resiste a pesar de todo. Pero también, ríe, se burla y juega, sin que le duelan los siglos. No vale de nada solemnizarla o desodorizarla.

Ella hasta nos disculpa la torpeza de seguir escribiendo.

\section{Poemas}

1) De 21 gramos (Ediciones En Danza, Bs. As., 2014)

\section{ENTRE DOS FONDOS, EN LA SUPERFICIE DEL MAR, TODO PESA MENOS}

Hay algo único en nadar cuando se acerca una tormenta.

Sorprende y tranquiliza ver boca arriba la velocidad con que el aire frota las partículas de los cúmulos grises y blancos.

Se puede con cada brazada tocar la intemperie, mar adentro.

Nadás de espaldas. Y tus ojos flotan con tu cuerpo, sin resistirse, en otras aguas, en un archipiélago de nubes entre la visible consistencia y la más transparente inconsistencia.

La corriente te lleva a donde quiere, rendido a su deseo y su fuerza.

Pensás que también así debería flotar tu pequeña historia, sobre el doble fondo, entre toneladas de relámpagos y el sordo respirar de los peces. 


\section{CADA PRODUCTO TIENE ALGÚN INCONFESADO DEFECTO}

Cada producto en sí tiene bien callado algún inconfesado defecto de fábrica: una naturaleza insustancial para evitar el remordimiento y la necesidad. Por eso cada día uno junta la basura como una abreviatura de la larga cadena de promesas y voluntades torcidas.

Te das cuenta de que uno también fabrica esta clase de cosas: palabras elásticas que se cortan, palabras pelotas que revientan, palabras molotov que se apagan.

Uno afila el lápiz, desde el totem al jeroglífico, y piensa en el futuro con la misma fe de los atletas. Ningún triunfo llega de esa parte.

Apenas si entre montañas de desperdicios y sueños uno podría lograr una mínima diferencia.

Una sola, antes de la imposible perfección del final.

Y a eso habría que llamarlo: Poesía.

\section{2) De Pasiones de la línea (poemas de Nicolás de Cusa) (Ediciones En Danza, Bs. As., 2008)}

\section{VIDA DE POESÍA}

No es sino una exageración

por la que mentimos una biografía, «un terremoto continuo o una fiebre eterna».

¿Quién podría en tal estado, por ejemplo, atarse los cordones de los zapatos, lavarse el culo tanto como la cara y 
562 Tropelías. Revista de Teoría de la Literatura y Literatura Comparada, 29 (2018)

Osvaldo Picardo

escupir la mala conciencia

con que se escribe de la injusticia?

Los personajes de la poesía

no están en los poemas que hemos hecho.

Son el poeta de sesenta años

que según Giannuzzi

«la época incorporó a su injuria»,

pero también, las loquitas angustiadas

que te despiertan a la madrugada;

y el delicado Sufeno al que Catulo

criticaba con una rara compasión.

Ni hablar de los borrachos de Alexander Blok

que «creen que algún dios los trajo acá

para que besaran el viento y la nieve...»

No basta con abrir el Libro de la Poesía

y leer en público. La luz no es suficiente.

Está en otra parte, y nos abandona

en la mesa, ante una verdad ilegible.

\section{EL ARTE DE LA PESCA}

\section{a Ettore, il mio amico}

En la escollera, las cañas anuncian

algo siempre inminente. La espera

del pescador sucede al primer pez.

Parece mentira, pero

lo que ya sucedió es lo que se espera,

aunque no vuelva a suceder.

La metáfora nos tienta y te preguntás

si no será una exageración que cada acto

de nuestras vidas signifique algo más

que lo que pasa. Las cosas están ahí

y el dedo que las muestra no es «las cosas». 
Tironea debajo y se resiste una corvina de esas que pesan más en las manos del pescador que en la balanza.

Se sabe que es corvina antes de que salga, hasta antes de que elijamos la carnada.

Luego, puede repetirse el truco, el anzuelo, la tanza, la plomada.

Pero el pez no vuelve a picar $\mathrm{y}$ tal vez no vuelva a hacerlo.

Con esa incertidumbre, se prende el farol y miramos cómo oscurece. 